\title{
OPINIONS OF MEDICAL STUDENTS ON THE PRE-GRADUATE SCIENTIFIC ACTIVITIES - HOW TO IMPROVE THE SITUATION?
}

\author{
Juraj Mokrya, Daniela Mokrab
}

\author{
${ }^{a}$ Department of Pharmacology, Comenius University, Jessenius Faculty of Medicine, Martin, Slovakia \\ ${ }^{b}$ Department of Physiology, Comenius University, Jessenius Faculty of Medicine, Martin, Slovakia \\ e-mail:mokry@jfmed.uniba.sk
}

Received: March 29, 2006; Accepted (with revision): March 6, 2007

Key words: Medical school education/Undergraduate research/Postgraduate scientific medical research.

Background: The number of medical undergraduates taking part in Student Scientific Activities (SSA) at Jessenius Faculty of Medicine Comenius University in Slovakia remains low. The aim of this study was to discover some of the factors responsible and suggest improvements.

Methods: An anonymous 30-item questionnaire was devised and sent to 245 medical undergraduates (UG) of the 1st, 2nd, 3rd and 5th years.

Results: Foreign fellowships, postgraduate research, assistant posts at universities and financial incentives were cited as the main positive motivators for participation in UG student scientific research. Characteristics in tutors that encouraged student research were scientific knowledge, giving time to students and enthusiasm for research while poor infrastructure, tutor lack of time/interest, own time constraints, weak career motivation and lack of information were the strongest discouraging factors.

Conclusion: Involvement of students in SSA is influenced by many factors. To increase the number of students taking part in SSA, student research and/or continuing to Ph.D and scientific career, these factors need to be addressed by medical schools.

\section{INTRODUCTION}

Scientific research is indispensable to modern medicine and undergraduate (UG) scientific work contributes to future professions. It also widens knowledge in specific fields of medicine ${ }^{1}$. However in Slovakia, despite the high declared interest of around $85 \%$ of medical students at Jessenius Faculty of Medicine Comenius University (JFMCU), only around $5 \%$ actually take part in student research ${ }^{2}$. Similarly, the number of medical graduates choosing a career in medical research is insufficient ${ }^{3}$. Kupfer et al. assumed that the early identification and recruitment of students at the undergraduate level might solve this problem ${ }^{4}$.

The aim of this survey was to determine what factors positively and negatively influence such behaviour and outline remedial measures.

\section{METHODS}

An anonymus 30-item questionnnaire was devised to 245 medical students of the $1^{\text {st }}, 2^{\text {nd }}, 3^{\text {rd }}$ and $5^{\text {th }}$ study years at JFM CU. The questions were divided into those aimed at determining (1) actual involvement of students in student scientific acitvities (SSA) and what factors increased enthusiasm for SSA, (2) the interest in Ph.D study programmes and scientific career, (3) tutor characteristics and (4) discouraging factors from SSA.

\section{RESULTS}

The return rates of distributed questionnaires were as follows: 2nd year $99 \%$, 3rd year $94 \%$, 5th year $43 \%$ and 1 st year $35 \%$.

Financial incentives, foreign scholarships, post graduate opportunities and assistant posts in universities for those with SSA experience were given as the most important motivators (Fig. 1). The results showed that 30-60\% of medical UG wanted to continue in research and post graduate research (60\% year 1, $42 \%$ year 2, $52 \%$ year 3 , $31 \%$ year 5) and about half of them want to work in the similar field of medical science. Scientific knowledge, time for students and enthusiasm for scientific research proved to be the most desirable characteristics in tutors (Fig. 2). Insufficient budgets, and infrastructure and lack of tutor time were deterring factors (Fig. 3). Time constraints due to study load or extra curricular activities, dearth of information about SSA (especially in the $1^{\text {st }}$ study year) and weak professional motivation were factors discouraging UG research (Fig. 4).

\section{DISCUSSION}

Rapid expansion and progress in biomedical research is transforming medical care. The physician investigator with knowledge of fundamentals and enthusiasm for research plays a key role in translating the progress in ba- 
sic research into clinical practice. However, the number of physicians trained to play this role is inadequate ${ }^{5}$. Encouragement of students at the undegraduate level may solve the problem ${ }^{4}$.

Student research either mandatory, or elective, or as an extra curricular activity is a part of modern medical school training, In many countries, research education is a mandatory part of medical training and extracurricular research projects provide additional opportunities for students ${ }^{6}$.

However at JFMCU in Slovakia, research was not part of medical training and student research is considered only as an extracurricular activity. Since 1997, we have observed an increasing interest but the numbers in this region are low, compared to other countries ${ }^{2}$. If the number of participants in the Student Scientific Conference is any indication, only 58 from 600 medical students (less than $10 \%$ ) presented their research at the congress in 2005 compared to $31 \%$ students from Helsinki and 35/91 published as $\mathrm{UGs}^{1}$. At the Medical Faculty in Wurzburg, Germany, the doctoral dissertation with a scientific basis is mandatory for the degree of doctor of medicine ${ }^{7}$. Thus, an inclusion of the SSA into the curriculum of JFM CU seems to be the major task for future.

Since the scientific activities at the medical school are voluntary, any other form of motivation for students should be used, for example financial motivation. Salomon et al. noted that in a climate of declining numbers of phy-

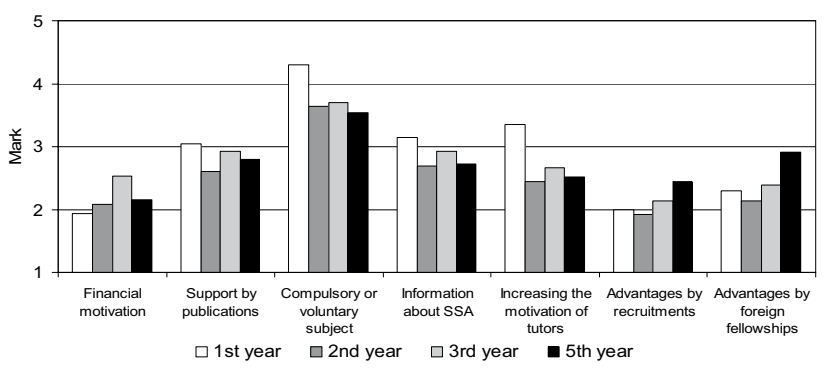

Fig. 1. Factors increasing an interest in SSA. $(1=$ the most important $)$.

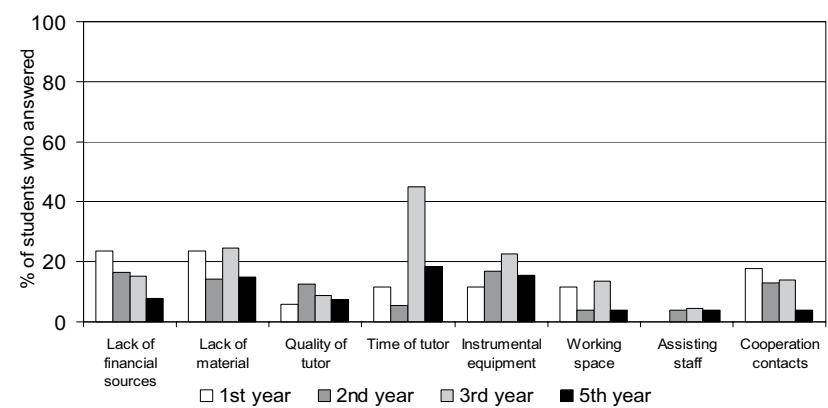

Fig. 3. Factors causing the slowing down or stopping the SSA. sician scientists, medical student research fellowships may present a solution, a critical „turn-on“, allowing students to consider research early in their careers. The task of our medical school then will be to support student research along these lines, provide proper information and in the ways suggested by the results, motivate them ${ }^{5}$. Since the program supporting the SSA in the form of scholarships for the best students was introduced, at JFM CU number of students presenting at annual SSC significantly increased (from 9 students in 1997 to 40 students in 2003 and 2004, and 58 students in 2005). In addition, the best presentations at SSC are awarded by financial prices. As we demonstrated also in our questionnaire, the financial support was marked as an important factor increasing the interest of students in the SSA.

Furthermore, since an active participation in the SSA became one of the selection criteria for the foreign fellowships and better professional opportunities after the graduation, this task was indicated as other strong motivation factor for the SSA. In addition, thanks to an entry of Slovakia to European Union, JFM CU increased the number of places for post-graduate students, where a participation in student research is one of the basic selection criteria. Our results showed that $30-60 \%$ of medical students want to continue in the research and in the postgraduate study, while about half of them want to work in the similar field of science. As we could observe, at JFM $\mathrm{CU}$ most of the PhD students were active participants at

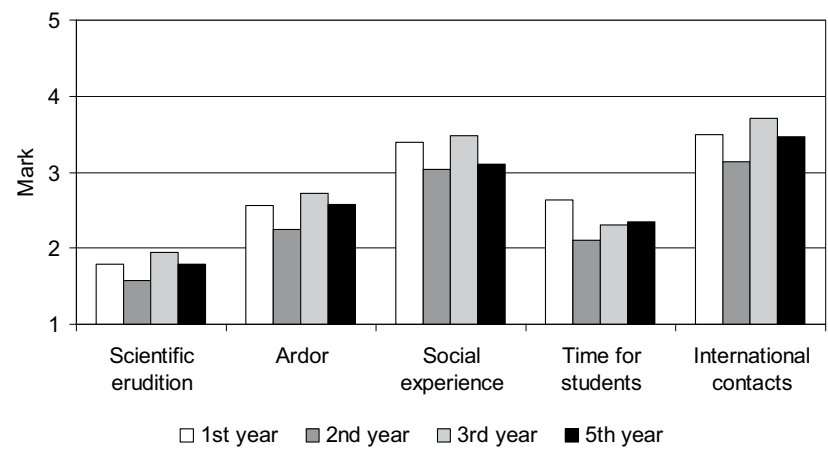

Fig. 2. Desired tutors' characteristics. ( 1 = the most important).

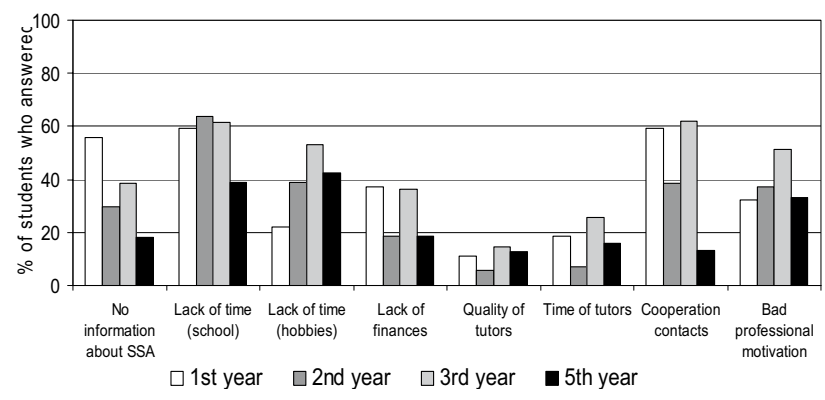

Fig. 4. Factors discouraging from the SSA. 
student scientific conferences in the last years. Several studies confirmed that the pre-gradual interest in scientific activities resulted in positive relation to research also after the finishing the university ${ }^{1,7}$. Moreover, students who gained an extracurricular experience publish significantly more articles after the graduation than students without such experience ${ }^{6}$.

Nevertheless, because many students miss the relevant information about the SSA, popularization of the student research among students became very important ${ }^{8}$. Similarly to our results, students of the $1^{\text {st }}$ year at Faculty of Medicine in Zagreb showed high interest in research, but their global knowledge about it was insufficient ${ }^{9}$. Instruction courses or lectures in research methods may answer students' questions and elucidate many facts and consequences. Approximation of the science to students thanks to better availability of Internet and other information technologies ${ }^{10}$, and higher interest of teachers in the SSA may further improve the knowledge about the SSA and their advantages not only in students, but may help to obtain a lot of results by rather low costs by departments and clinics. In Würzburg tutors, student research was considered as very important in maintaining the qualitative and quantitative level of publication activity of the University ${ }^{7}$. Thus, supporting the pre-gradual SSA may finally help to solve the problematic situation in Slovakia, where universities miss a whole generation of teachers and young scientific professionals with 5-10 years practice due to brain drain etc. ${ }^{11}$

On the other hand, without an adequate appraise of teachers it is impossible to reach desiderative resolution and interest in involving to the scientific activities in students. According to our questionnaire, the most desirable characteristics of tutors are scientific erudition, ardor for scientific work, and having enough time for students. However, teachers should improve not only the medical knowledge of the students, but also their moral characteristics, creative thinking, social feeling, language skills, and computer communication mastering. Positive impact of the pre-gradual research activities may then increase the chances of students to get an appropriate job, as well as to encourage them to enter academic and research careers.

\section{CONCLUSION}

The pre-graduate research activities contribute to better profiling of students and to improvement of their professional growth, as well as to better results in the postgraduate study. Since the involvement of students and tutors in the SSA is influenced by many factors, the main task of medical schools is to support the student research programs, to inform adequately about advantages of SSA, and to motivate the students for scientific activities.

\section{LIST OF ABBREVIATIONS}

SSA - Student Scientific Activities

SSC - Student Scientific Conference

JFMCU - Jessenius Faculty of Medicine, Comenius University

$\mathrm{PhD}$ - post-graduate

\section{REFERENCES}

1. Remes V, Helenius I, Sinisaari I. Research and medical students. Med Teacher 2000; 22:164-7.

2. Mokry J, Sevecova D, Sulaj M. Student scientific activities at Jessenius Faculty of Medicine, Comenius University in Martin - current state and its future. Bratisl Lek Listy 2004; 105:25-9.

3. Campbell EG, Weissman JS, Moy E, Blumenthal D. Status of clinical research in academic health centers. View from the research leadership. JAMA 2001; 286:800-6.

4. Kupfer DJ, Hyman SE, Schatzberg AF, Pincus HA, Reynolds CF. Recruiting and retaining future generations of physicians scientists in mental health. Arch General Psychiatry 2002; 59:657-60.

5. Solomon SS, Tom SC, Pichert J, Wasserman D, Powers AC. Impact of medical student research in the development of physician-scientist. J Investig Medicine 2003; 51:149-56.

6. Reinders JJ, Kropmans TJB, Cohen-Schotanus J. Extracurricular research experience of medical students and their scientific output after graduation. Med Education 2005; 39:237.

7. Altunbas A, Cursiefen C. Forschungsaktivität von Medizinstudenten in Deutschland am Beispiel der Universitätsklinik Würzburg. Deutsche Medizinische Wochenschrift 1998; 8:617-20.

8. Hanacek J. Undergraduate medical education in Slovakia - present state and future needs. Bratisl Med J 2001; 102:438-43.

9. Vodopivec I, Vujaklija A, Hrabak M, Lukic IK, Marušic A, Marušic M. Knowledge about and Attitude towards Science of First Year Medical Students. Croat Med J 2002; 43:58-62.

10. Mesko D. Appliance and information technologies versus patient, versus physician-teacher, versus student (reality or science fiction?). Bratisl Lek Listy 2000; 101:675-83.

11. Kukurova E, Bernadic M, Holomanova A, Javorka V, Duris I. Profesionalism of theoretical and clinical subjects teachers in schools of medicine. Bratisl Lek Listy 2000; 101:412-4. 